\title{
Concentration of marc extracts by membrane techniques
}

\author{
C. Hodúr ${ }^{\mathrm{a} *}$, Sz. Kertész ${ }^{\mathrm{b}}, \mathrm{S}$. Beszédes ${ }^{\mathrm{a}}$, Zs. Lászlóa ${ }^{\mathrm{a}}$ G. Szabóa \\ ${ }^{a}$ Department of Technical and Process Engineering, Faculty of Engineering, \\ University of Szeged, H-6725, Szeged, Moszkvai krt 5-7, Hungary \\ email: hodur@mk.u-szeged.hu \\ ${ }^{\mathrm{b}}$ PhD School of Environmental Sciences, University of Szeged, \\ H-6720, Szeged, Dugonics tér 13, Hungary
}

Received 20 August 2007; revised 20 December 2007; accepted 27 December 2007

\begin{abstract}
By-products obtained from red currant processing still contain large amounts of useful components, e.g. pectin. Pectin was extracted from red currant marc with water at a solid/liquid ratio of 1:10. To reduce the operating costs of further possessing, we concentrated the pectin solution by membrane separation, i.e. nanofiltration (NF) and reverse osmosis (RO).

The objectives of our work were to study the effects of the operating pressure and cross-volume flow rate on the flux and on the membrane separation concentration ratio in order to establish the optimum operating conditions and to evaluate the contributions of the fouling, cake and membrane resistances to the overall resistance.

Flat-sheet RO and a spiral-wound NF membrane were applied in the work.

The conductivity, the color, the viscosity and the TSS of the permeate and the concentrate were followed during the measurements.

Concentration by RO resulted in an increase of the TSS content to $4.2^{\circ}$ Brix; for NF the corresponding level was $8.8^{\circ}$ Brix. The membrane resistance and the fouling resistance were the determinant relative to the gel resistance.
\end{abstract}

Keywords: Concentration; Nanofiltration; Reverse osmosis; Flux; Red currant; Marc extract; Galacturonic acid; Pectin; Membrane resistance; Cross-volume flow rate

*Corresponding author.

Presented at the Third Membrane Science and Technology Conference of Visegrad Countries (PERMEA), Siofok, Hungary, 2-6 September 2007. 


\section{Introduction}

The recycling of food and agricultural wastes is at times an environmental problem. Moreover, these wastes often contain considerable amounts of valuable components such as sugars, polysaccharides, antioxidants, colorants, etc. Today, economical and environmentally-friendly separation and concentration techniques are available for the recovery of some of these agents. Like other fruit marcs, red currant marc contains many useful components that could be extracted before its use as fertilizer, animal feed or bio-fuel. One of these components is pectin, which has been used in the food industry as a thickener, a texturizer, an emulsifier, a stabilizer, and a gelling agent in jams and jellies. It has also been utilized as a filler or stabilizer in confections, dairy products, fruit preparations, bakery fillings, icings and frostings. Other applications include fat replacement in spreads, salad dressings, ice cream and emulsified meat products [1].

Marc can be extracted with hot water at a solid/solvent ratio of $1: 10$. The extracted pectin then can be precipitated with alcohol, but this process would be more effective if the extract were concentrated before precipitation. This dilute solution could be concentrated by evaporation or membrane separation. Membrane-based concentration is becoming increasingly popular, as it offers a number of advantages over conventional concentration methods, e.g. it is less energy-demanding and more economical than competing concentration technologies [2-4].

Any membrane techniques, nanofiltration (NF) and reverse osmosis (RO) are effective methods for the concentration of fruit juices [5-8].

The aim of our work was to study the effects of NF and RO on red current marc extracts. We investigated the effects of the operating pressure and the cross-volume flow rate on the flux and on the concentration ratio achieved by membrane separation in order to determine the optimum operating conditions, and we also evaluated the contributions of fouling resistance, gel layer resistance and membrane resistance to the overall resistance. The behavior of RO and NF processes are usually measured in terms of permeate flux $(J)$ and retention rate (SR). The flux is expressed as

$$
\begin{aligned}
J & =\frac{V}{A \tau}=\frac{\Delta p}{\eta R_{\mathrm{t}}} \\
& =\frac{\Delta p}{\left(\eta R_{\mathrm{M}}+R_{\mathrm{G}}+R_{\mathrm{F}}\right)} \quad\left(\mathrm{L} \mathrm{m}^{-2} \mathrm{~h}^{-1}\right)
\end{aligned}
$$

where $V$ is the permeate volume $\left(\mathrm{L}, \mathrm{dm}^{3}\right), A$ is the effective membrane area $\left(\mathrm{m}^{2}\right), \tau$ is the time $(\mathrm{h})$ necessary for the $V$ liters of permeate to be collected, $\Delta p$ is the trans-membrane pressure (TMP) applied (Pa), $\eta$ is the viscosity (Pas), $R_{\mathrm{t}}$ is the total resistance of the system $\left(\mathrm{m}^{-1}\right), R_{\mathrm{M}}$ is the resistance of the membrane $\left(\mathrm{m}^{-1}\right), R_{\mathrm{G}}$ is the resistance of the gel layer (cake) formed on the surface of the membrane $\left(\mathrm{m}^{-1}\right)$ and $R_{\mathrm{F}}$ is the internal fouling resistance $\left(\mathrm{m}^{-1}\right)$.

The retention rate $\left(\mathrm{SR}_{i}\right)$ for a given solute is calculated as

$\mathrm{SR}_{i}=1-\frac{c_{\mathrm{p}}}{c_{\mathrm{f}}}$

where $c_{\mathrm{p}}$ and $c_{\mathrm{f}}\left(\%\right.$ or $\left.\mathrm{mg} \mathrm{dm}^{-3}\right)$ are the concentrations of the given component in the permeate and in the feed, respectively. In the experiment, the "concentration" is the conductivity value of the permeate or the feed; in this way, the retention means the retention mainly of ions.

The concentration ratio $(\mathrm{CR})$ was calculated from the volumes of the concentrate $\left(V_{\mathrm{fc}}\right)$ and of the feed $\left(V_{\mathrm{f}}\right)$ as

$$
\mathrm{CR}=\frac{V_{\mathrm{f}}}{V_{\mathrm{fc}}}
$$

\section{Materials and methods}

Red currant (Ribes rubrum) press-cake was used in our experiments. The marc samples came from a Hungarian berry farm, Fitomark $94 \mathrm{Ltd}$. 
Table 1

Properties of the membranes

\begin{tabular}{lllll}
\hline & RO1 & RO2 & NF1 & NF2 \\
\hline Membrane type & Sheet ACM2 & Sheet SG & Spiral-wound & Sheet DL \\
Material & Polyamide & Composite & Polyamide & composite \\
Effective superficial surface area $\left(\mathrm{m}^{2}\right)$ & 0.18 & 0.0156 & 0.3 & 0.0156 \\
Max. pressure (bar) & 70 & 70 & 40 & 40 \\
pH range & $2-11$ & $2-11$ & $2-11$ & $2-11$ \\
$\mathrm{NaCl}$ retention (\%) & 99.9 & 98.5 & - & - \\
$\mathrm{CaCl}_{2} / \mathrm{MgSO}_{4}(\%)$ & - & - & 94 & $96^{\mathrm{a}}$ \\
\hline
\end{tabular}

${ }^{\mathrm{a}}$ Retention.

After pressing, the marc was deep-frozen until extracted. The $\mathrm{pH}$ and the water content of the red current press-cake was 6.18 and $74.7 \%$, respectively. For the conventional extraction, an Armfield pilot plant solvent extractor was used. The solvent was water, and the temperature of extraction was $80^{\circ} \mathrm{C}$; the $\mathrm{pH}$ was neutral $(\mathrm{pH}=7)$. The quantity of sample was $100 \mathrm{~g}$ (wet), with TSS of $1^{\circ}$ Brix and the liquid/solid ratio applied was 40:1.

\subsection{Membrane separation}

Two flat-sheet RO membranes (ACM2-TRISEP and SG composite (CHEZAR spol. s r., Bratislava, Slovak)), one flat-sheet NF membrane (DL) (CHEZAR spol. s r., Bratislava, Slovak) and one spiral-wound NF membrane were used. The properties of these membranes may be seen in the Table 1.

In the experiments, a cross-flow filtration setup was used. The concentration was carried out at $20^{\circ} \mathrm{C}, 0.3 \mathrm{MPa}, 200 \mathrm{~L} \mathrm{~h}^{-1}$ for $\mathrm{NF}$ and with an RO cross-volume flow rate of $500-400 \mathrm{~L} \mathrm{~h}^{-1}$ (see Table 2). The TSS content of the feed varied between 0.9 and $1.2^{\circ}$ Brix.

\subsection{Analytical methods}

The conductivity, and the TSS of the permeate and the concentrate were determined with a Consort C535 conductivity meter and a refractometer, respectively. Pectin content was measured photometrically at $520 \mathrm{~nm}$ by the $m$-hydroxydiphenyl method, and expressed in galacturonic acid units [6].

\subsection{Resistances}

The membrane resistance $\left(R_{\mathrm{M}}\right)$ was calculated as the total resistance of pure water filtration, assuming that neither significant cake deposition nor gel layer formation and pore plugging or adsorption is prevalent. Accordingly, Eq. (1) can be simplified [9-12] as

$J_{\mathrm{w}}=\frac{V}{A \tau}=\frac{\Delta p}{\eta R_{\mathrm{t}}}=\frac{\Delta p}{\eta\left(R_{\mathrm{M}}\right)} \quad\left(\mathrm{L} \mathrm{m}^{-2} \mathrm{~h}^{-1}\right)$

where $J_{\mathrm{w}}$ is the pure water flux of the clean membrane.

The internal fouling resistance measures the contribution to the total hydraulic resistance arising during membrane separation by the material that is presumably strongly attached to the pores of the membrane and retained after the water rinsing phase at the end of the $\mathrm{NF} / \mathrm{RO}$

Table 2

Running parameters

\begin{tabular}{llll}
\hline & $q_{\mathrm{V}}\left(\mathrm{L} \mathrm{h}^{-1}\right)$ & TMP (bar) & $T\left({ }^{\circ} \mathrm{C}\right)$ \\
\hline NF & 200 & 30 & $20 \pm 1$ \\
RO & $400-500$ & 30 & $30 \pm 1$ \\
\hline
\end{tabular}


runs. The water rinsing step is believed to wash out any material (the formed cake of the gel layer) that is weakly attached to the membrane. $R_{\mathrm{F}}$ is calculated via Eq. (5) from water flux measurements on the fouled membrane after the NF/RO runs $\left(J_{\mathrm{w}}^{\prime}\right)$ :

$J_{\mathrm{w}}^{\prime}=\frac{\Delta p}{\eta\left(R_{\mathrm{M}}+R_{\mathrm{F}}\right)} \quad\left(\mathrm{L} \mathrm{m}^{-2} \mathrm{~h}^{-1}\right)$

The gel layer resistance $\left(R_{\mathrm{G}}\right)$ present before cleaning is the difference between the total resistances before and after cleaning. The total resistance before cleaning can be calculated from the steady-state flux of RO/NF at $\tau_{\infty}$. With this calculation system, the resistance caused by concentration polarization is included in this value.

\section{Results and discussion}

\subsection{Concentration by $N F$}

Fig. 1 demonstrates that the permeate flux of the red currant extract increased linearly with rising operating pressure during NF (NF1), but the flux rose only slowly in the higher pressure range, i.e. a saturated function. In response to elevated pressure, the permeate flux rose accordingly, which led to additional concentration at the membrane surface. It was observed that the flux exhibited a slowly increasing tendency. This tendency was observed to start at about $3.0 \mathrm{MPa}$.

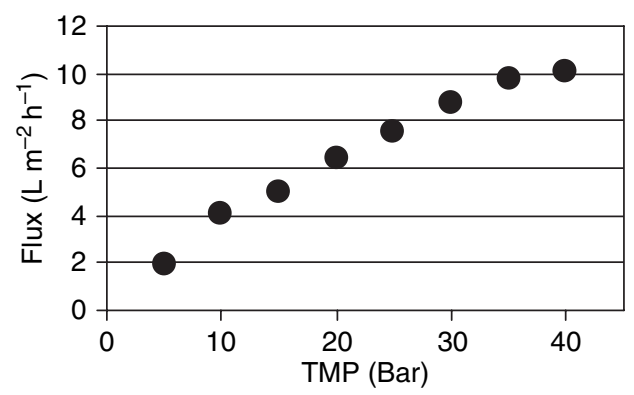

Fig. 1. Permeate flux of NF1 vs. operating pressure, cross-volume flow rate: $200 \mathrm{~L} \mathrm{~h}^{-1}$.

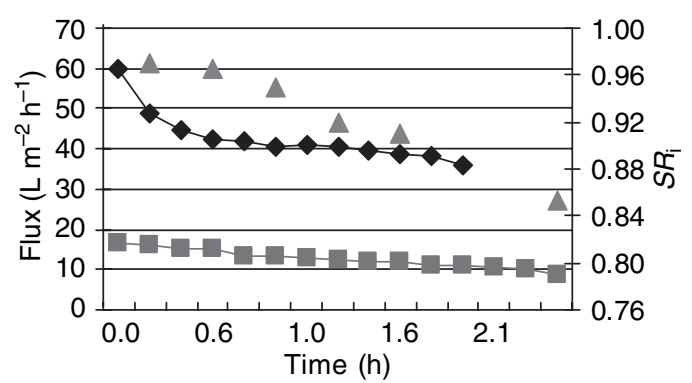

$\rightarrow-$ Flux NF1 $\bullet$ Flux NF2 $-S R_{\mathrm{i}}$

Fig. 2. Comparison of flux values at different NF membranes vs. time (pressure: $3.0 \mathrm{MPa}$, temperature: $20 \pm 1^{\circ} \mathrm{C}$, cross-volume flow rate: $200 \mathrm{~L} \mathrm{~h}^{-1}$ ).

The subsequent measurements were therefore made at 3.0 $\mathrm{MPa}$.

The permeate flux decreased as time progressed, and tended to become constant (Fig. 2.) As the run proceeded, the concentration at the surface of the membrane rose, which followed the addition of solute flux through the membrane, i.e. the retention rate $\left(\mathrm{SR}_{i}\right)$ decreased (Fig. 2).

The concentration ratio was 3.6 and 11 during NF1 and NF2, respectively. The total solid content of the concentrates at the end of the processing was 8.8 and $6.3^{\circ}$ Brix. The initial value was $0.9^{\circ}$ Brix.

\subsection{Concentration by $R O$}

The influence of the recycling capacity was investigated in the case of concentration by RO. The results are shown in Fig. 3, where the fluxes are plotted as a function of TMP. The permeate flux of the solution increased as a saturated function with rise of pressure and rise of the recycling capacity, in agreement with the literature data $[3,4,6,8]$ for similar solutions. This increase was not too pronounced because the determinant resistance was the fouling resistance, which was not affected by the recycling capacity. As shown in Fig. 3, the permeate flux increased with 


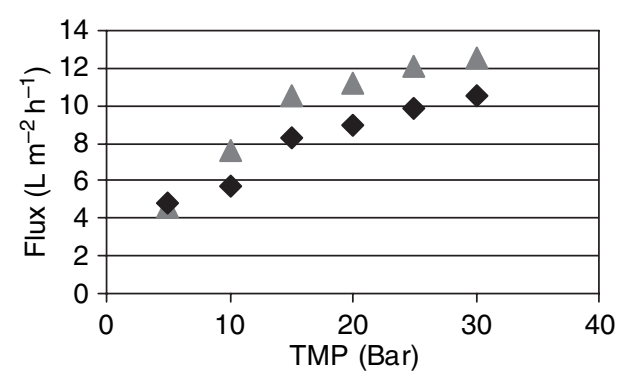

$$
\begin{aligned}
& \Delta \text { Extract of marc } 500 \mathrm{~L} / \mathrm{h} \\
& \text { Extract of marc } 400 \mathrm{~L} / \mathrm{h}
\end{aligned}
$$

Fig. 3. Flux of extract for different recirculation flow rates vs. TMP.

recirculation flow rate elevation, but progressed towards a steady state. There are a number of reasons for these trends. Due to the higher velocity at the surface as the concentration at the surface of the membrane decreases, a thinner gel layer/layer of concentration polarization was formed, and the gel layer resistance was reduced.

The concentration of red currant marc extract by $\mathrm{RO}$ was carried out at $3.0 \mathrm{MPa}$, with a recycling capacity $500 \mathrm{Lh}^{-1}$, on the basis of the previous results. As may be seen in Fig. 4, there was a great difference between the fluxes of the applied RO membrane systems. Both membranes had flat-sheet configuration, but they were made from different materials (Table 1)

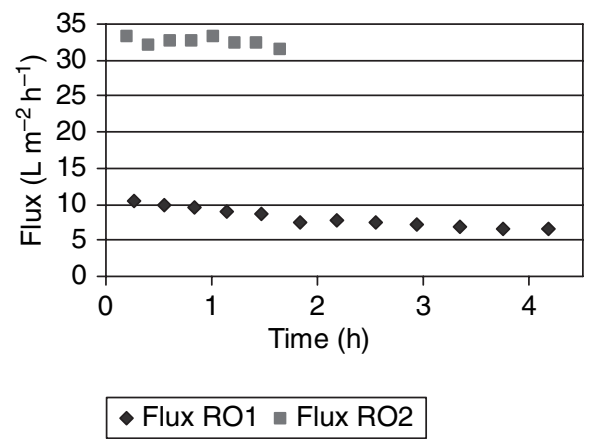

Fig. 4. Concentration of red currant extract marc vs. Time (TMP: 30 bar, temperature: $30 \pm 1{ }^{\circ} \mathrm{C}$, crossvolume flow rate: $500 \mathrm{~L} \mathrm{~h}^{-1}$ ).
Table 3

Main characteristics of the extract concentration

\begin{tabular}{llcc}
\hline & $\mathrm{SR}_{i}$ & $\mathrm{CR}$ & ${ }^{\circ}$ Brix \\
\hline RO1 & 0.96 & 3 & 4.2 \\
RO2 & 0.96 & 16.5 & 6.7 \\
NF1 & 0.85 & 3.6 & 8.8 \\
NF2 & 0.62 & 11 & 6.3 \\
\hline
\end{tabular}

and had different levels of $\mathrm{NaCl}$ rejection. A 3-fold higher permeate flux was measured for RO2 because of the lower total resistance.

The solid content of the permeate was practically zero. The solid content (expressed in ${ }^{\circ}$ Brix) of the concentrate increased from 0.9 up to 4.2 for RO1 and up to 6.7 for RO2. CR was 3 and 16 for $\mathrm{RO} 1$ and RO2, respectively (Table 3 ).

\subsection{Total and individual resistances}

One of the objectives of the study was to distinguish between the individual resistances and to determine their contributions to the overall resistance. The experimental results allowed determination of the individual components of the total resistance: the membrane resistance, the internal fouling resistance and the gel layer resistance. The membrane resistance was

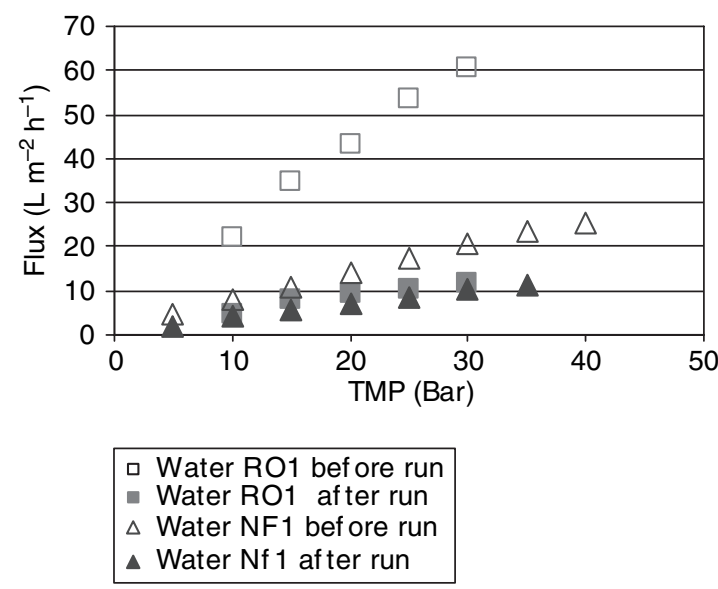

Fig. 5. Permeate fluxes of clean and fouled membranes vs. TMP. 
(a)

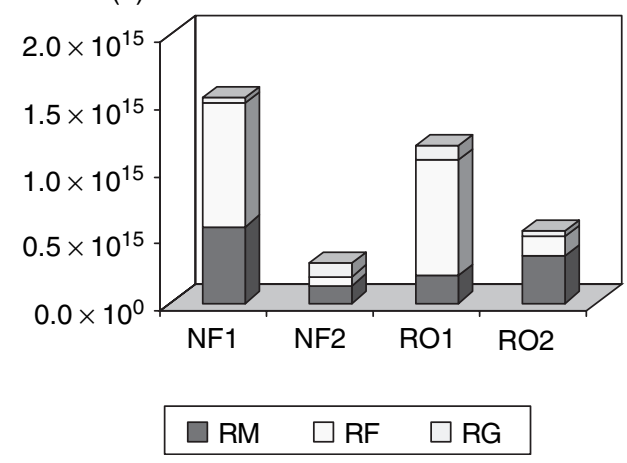

(b)

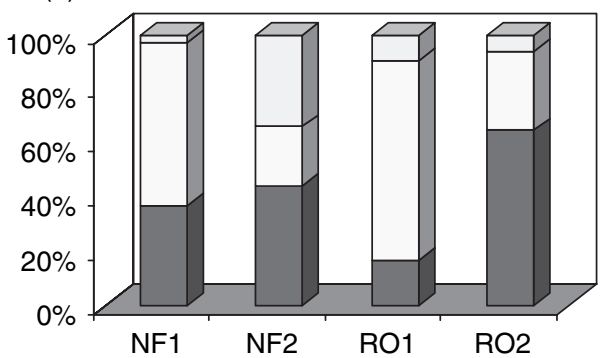

Fig. 6. Individual resistances in absolute value (a) and percentage (b).

calculated from the water flux data measured before NF and RO of the marc extract (water before run). In Fig. 5, large differences are observed between the clean and fouled RO and NF membranes.

It is clear from Fig. 6 that the membrane resistance and internal fouling resistance were important relative to the gel layer resistance (corresponding to Ref. [6]) for RO1, RO2 and NF1 as well. In the NF2 experiments, the tendency was slightly different: the proportions of the membrane, internal fouling and gel layer resistances were $44 \%, 22 \%$ and $34 \%$, respectively. This difference was due to the value of $R_{i}$. The retention of ions was less for the NF2 system, giving rise to a small concentration polarization between the surface of the membrane and the bulk, and a smaller gel layer resistance (and a large permeate flux).

\section{Conclusions}

These results revealed that the red currant marc extract could be concentrated successfully both by NF and RO; the permeate was clear, and there was neither colorant nor pectin loss.

- The optimum running pressure for both NF and RO systems was $3.0 \mathrm{MPa}$; the $J$ vs. TMP functions were of saturated type in all cases.
- The maximum total solid content for NF1 was $8.8^{\circ}$ Brix, but due to the very high total resistance $\left(1.5 \times 10^{15} \mathrm{~m}^{-1}\right)$, the permeate flux was approximately four times lower than that for NF2 (average flux for NF1: $12.44 \mathrm{~L} \mathrm{~m}^{-2}$ $\mathrm{h}^{-1}$ and for NF2: $40.99 \mathrm{~L} \mathrm{~m}^{-2} \mathrm{~h}^{-1}$ ), while the TSS of the NF2 concentrate was $6.3^{\circ}$ Brix.

- The maximum total solid content for RO2 was $6.7^{\circ}$ Brix and the permeate flux was also higher in this case $\left(32.43 \mathrm{~L} \mathrm{~m}^{-2} \mathrm{~h}^{-1}\right)$ than for RO1 (average flux for RO1: $8.17 \mathrm{~L} \mathrm{~m}^{-2}$ $\mathrm{h}^{-1}$ and TSS for RO1: $4.2^{\circ}$ Brix).

- The membrane resistance and the fouling resistance were the determinants relative to the gel resistance.

- The $R_{\mathrm{F}}$ and $R_{\mathrm{G}}$ ratio was less than 1 for the NF2 system only (the values for NF1, NF2, RO1 and RO2 were 19.12, 0.68, 7.69 and 4.80 , respectively), due to the smallest SR value being observed for the NF2 system. The small SR value meant less fouling than in the other systems, and hence the ratio of the gel resistance was higher for NF2, but its absolute value was quite the same as in the other cases.

- For the RO1 system, the measured gel layer resistances were $8.32 \times 10^{14}$ and $1.04 \times 10^{15}$ at cross-volume flow rate of $500 \mathrm{~L} \mathrm{~h}^{-1}$ and $400 \mathrm{~L} \mathrm{~h}^{-1}$, respectively. This means that an $80 \%$ increase in the recycling capacity caused only a $25 \%$ decrease in the gel resistance. 


\section{Acknowledgements}

The authors are grateful for support of this work by KPI - GAK2-MEMBRAN5 (OMFB009972/2005) and the RET07/2005 project.

\section{Nomenclature}

$A \quad$ effective membrane area $\left(\mathrm{m}^{2}\right)$

$c_{\mathrm{p}} \quad$ concentration of permeate $(\%$ or $\mathrm{mg}$ $\mathrm{dm}^{-3}$ )

$c_{\mathrm{f}} \quad$ concentration of feed ( $\%$ or $\mathrm{mg} \mathrm{dm}^{-3}$ )

$J$ permeate flux $\left(\mathrm{L} \mathrm{m}^{-2} \mathrm{~h}^{-1}\right)$

$J_{\mathrm{w}} \quad$ pure water flux of the clean membrane $\left(\mathrm{L} \mathrm{m} \mathrm{m}^{-2} \mathrm{~h}^{-1}\right.$ )

$J_{\mathrm{w}}^{\prime} \quad$ pure water flux of the fouled membrane $\left(\mathrm{L} \mathrm{m}^{-2} \mathrm{~h}^{-1}\right)$

NF1 flat sheet DL

NF2 spiral wound membrane

$R_{\mathrm{G}} \quad$ resistance of the gel layer (cake) formed on the surface of the membrane $\left(\mathrm{m}^{-1}\right)$

$R_{\mathrm{F}} \quad$ internal fouling resistance $\left(\mathrm{m}^{-1}\right)$

$R_{\mathrm{M}} \quad$ resistance of the membrane $\left(\mathrm{m}^{-1}\right)$

$R_{\mathrm{T}} \quad$ total resistance of the system $\left(\mathrm{m}^{-1}\right)$

RO1 sheet ACM2-TRISEP

$\mathrm{RO} 2$ sheet SG composite

$\mathrm{SR}_{i} \quad$ retention ratio

$V \quad$ volume of permeate $\left(\mathrm{dm}^{3}\right)$

$V_{\mathrm{c}} \quad$ volume of concentrate $\left(\mathrm{dm}^{3}\right)$

$V_{\mathrm{f}} \quad$ volume of feed $\left(\mathrm{dm}^{3}\right)$

$\Delta p \quad$ applied trans-membrane pressure $(\mathrm{Pa})$

$\eta \quad$ viscosity (Pas)

$\tau \quad$ time (h)

\section{References}

[1] K. King, Pectin untrapped natural resources, Food Sci. Technol. Today, 3 (1993) 147-152.
[2] B. Kshama and J.C. Martin, New developments in membrane based separations, Trends Biotechnol., 17 (5) (1999) 197-200.

[3] K. Waldron (Ed.), Handbook of Waste Management and Co-product Recovery in Food Processing, Woodhead Publishing Ltd, Cambridge, 2007, pp. 198-216.

[4] Sz. Bánvölgyi et al., Concentration of blackcurrant (Ribes nigrum L.) juice with nanofiltration, Desalination, 200 (2006) 535-536.

[5] B. Gilewicz-Lukasik, S. Koter and J. Kurzawa, Concentration of anthocyanins by the membrane filtration, Sep. Purific. Technol., doi: 10.1016/j. seppur.2006.03.026.

[6] L. Xu and S. Wanf, The Ginkgo Biloba extract concentrated by nanofiltration, Desalination, 184 (2005) 305-313.

[7] I. Vincze et al., Concentration of sea buckthorn (Hippophae rhamnoides L.) juice with membrane separation, Sep. Purific. Technol., doi: 10.1016/j seppur.2006.06.020.

[8] Sz. Bánvölgyi, I. Kiss, E. Békássy-Molnár and Gy. Vatai, Concentration of red wine by nanofiltration, Desalination, 198 (2006) 8-15.

[9] M. Carabasa, A. Ibarz, S. Garza and G.V. BarbosaCánovas, Removal of dark compounds from clarified fruit juices by adsorption processes, J. Food Eng., 37 (1998) 25-41.

[10] E.J. de la Casa, A. Guadix, R. Ibanez and E.M. Guadix, Influence of $\mathrm{pH}$ and salt concentration on the cross-flow microfiltration of BSA through a ceramic membrane, Biochem. Eng. J., 33 (2007) 110-115.

[11] C. Psoch and S. Schiewer, Resistance analysis for enhanced wastewater membrane filtration, J. Membr. Sci., 1280 (2006) 184-297.

[12] J.F. Lapointe, S.F.Gautier, Y. Pouliot and C. Bouchard, Fouling of a nanofiltration membrane by a $\beta$-lactoglobulin tryptic hydrolysate, J. Membr. Sci., 253 (2005) 89-102. 